\title{
Translation and Paratexts (Translation Theories Explored), Written by Batchelor Kathryn, 2018, 202 pp, £ 25.64 (Kindle), ISBN: 978-1-351-11011-2 (EBK)
}

\author{
HUANG Jian \\ Central University of Finance and Economics, Beijing, China
}

Paratexts, born as an important branch of literary study, has now become a new theoretic topic in translation studies. This book, Translation and Paratexts, is the latest monograph on this topic characterized by a critical review of the development of the concept and its application in various fields, especially in the field of translation studies. For the students and researchers in translations studies, interpretation studies, literary translation, and even translation practitioners, this book is a quality source of relevant knowledge and inspiration. And it is made up of three parts.

The first part (from Chapter 1 to Chapter 3) deals with the conceptualization of paratext by its pioneer, Gennette, in literary context and its further development in the domain of translation and modern media. Chapter 1 makes a clean and clear review of Genette's theorization of paratext by analysing the three defining elements (material attribution, functional classification, and authorial intention), the internal conflicts (mainly the disagreement between authorial intention and other defining factors), and the typology (special, temporal, substantial, pragmatic, and functional). What is more, Genette's theorization of translation as paratext and translation as text with its own paratext is discussed in an independent section. Chapter 2 examines how the concept of paratext is applied, modified, and researched in the domain of translation (or how it inspires translation study) with the idea of translation per se as paratext to original work and translation as independent work with its own paratext explored in a more detailed way. Chapter 3 analyses how the original conceptualization of paratext is challenged and enriched in the domain of media studies.

The second part (from Chapter 4 to 6 ) is a collection of three case probes into paraxtexts. Chapter 4 looks at the paratexts of English versions of Nietzsche's works. It is found that while paratext of translation can shape the way in which translated texts are read, the translated book as a whole (the text and paratext combined) also fulfills a paratextual function in the sense that it serves as a threshold to the author and the author's reputation rather than the original text. It is stressed that "viewing translations as a paratext in this way has the advantage of stressing the process of interlingual transfer in the reception of ideas across cultures and foregrounding the fact that many

\footnotetext{
Acknowledgement: This research is supported by “The State Scholarship Fund” (Grant NO. 201706495030) and 2014 CUFE SFS Key Academic Research Project Fund (Project title: Undergraduate Translation Program From Perspective of Professional Development).

HUANG Jian, Ph.D., Associcate Professor, Department of Translation and Interpretation, School of Foreign Studies, Central University of Finance and Economics, Beijing, China.
} 
readers access ideas in a form that is mediated by a translator and others involved in publication of translations". Chapter 5 examines the paratexts for western translation theories translated into Chinese. It is found that three major themes are manifested in these paratexts: making the foreign serve China, eurocentricity and translation theory as knowledge, implying the function of paratext as carrier of its writer's critical opinion of what is translated. Chapter 6 looks at paratexts for TV (Walter Presents). It can be seen from this case study that audiovisual products boast diversity of paratexts (sub) categories (e.g., curation, branding, industry-created paratext, and viewer-created paratext), selectivity of messages conveyed via industry-created paratexts, and plurality of paratextual messages from various sources which might conflict each other in conditioning audiences' entrance to texts. Three cases seem to be chosen deliberately to represent the genres that are less researched in terms of paratexts such as philosophy, translation theory and TV works, and different (sub)categories of paratexts and issues discussed in Part 1 such as substantial paratext, paratexts by its producers, translation as paratexts etc. These three case studies combined together confirm that concept of paratext originated from literature studies can not only be well applied to other contexts but also can be extended and enriched in terms of paratexual content and function in the process of application. They suggest that paratext is in essence an open system capable of involving infinite themes and serving diverse functions and deserves to be well explored in specific context case by case for a better understanding of both the works concerned and the concept of paratext itself.

The third part (Chapters $7 \&$ 8), based on insight gained from Part $1 \& 2$, aims to develop a framework for studying translation-related paratexts. Chapter 7 focuses on the terminological issue of paratext by justifying its use, refining it, and expanding the five parameters in Gennett's typology. The superiority of the term "paratext" over other similar terms is justified firstly in stressing the established tradition of the term in various translation-related disciplines and then in analysing main terms with paratextual implication (frame and framing, extratext, metatext, paratranslation) in relation to the author's redefinition of paratext. Paratext is redefined, on the ground of practical adequacy, as "a consciously crafted threshold for a text which has the potential to influence the way(s) in which the text is received" (Batchelor, 2018, p. 142), which is characterized by its openness in allowing for paratexts of a wider range of texts and producer \& receiver perspectives and its constraints in excluding broader context and happenstance out of the scope of paratexts. The five parameters underlying Gennett's typology are expanded so that they can be better aligned with contemporary translation studies, thus justifying the newly proposed definition. From the justification, redefinition and expansion emerges both the complexities involved in developing paratextual typology for translation study and potentials inherent in this line of inquiry. Chapter 8 examines the existing and prospective topics and methodologies for translation-related paratext study from four perspectives: product-oriented research, process-oriented research, interpreting studies, and translation as a paratext. In each of the research branches, specific research topics and their methodological challenges are discussed.

As compared with the seminal book in this field: Paratexts: Thresholds of Interpretation (Literature, Culture, Theory) (Gennette, 2010), the most striking contribution of this book lies in its being informative and critical at the same time. It gives a very clear review of existing paratext literature, informing readers of how it is originally conceptualized in literature studies; how such original conceptualization is vested with internal confrontation; and how such conceptualization is applied, challenged, and enriched (expanded) across disciplines 
and/or contexts. The readers who, for various reasons, have no access to the original idea of Gennette and other relevant literature are expected to develop a critical bird-eye view of the field by reading the book: its conceptual strength \& weakness and its existing and future researches. What is more, the book is coherently organized such a way that the key concepts and issues of paratexts brought up in Part 1 are revisited one way or another in Part 2 \& 3, thus facilitating readers' efficient acquisition and grasp of the key ideas. In other words, the book can be said to be example of quality content delivered in efficient form.

Yet it is not without problem. The original conceptualization could have been more critically analyzed. While pointing out the internal conflicts, the books fail to be critical about other aspects of the original conceptualization such as the three defining functions of paratext proposed by Genette. On the one hand, it is harder to distinguish the peritexts that "comment on" text and those that "extend, ramify, and modulate" text, making the conceptual borderline blurry. On the other hand, there does not seem to be much point in making such a distinction because those who "extend, ramify, and modulate" the text can serve well as a threshold to the text. Given the book is entitled Translation and Paratext with the focus on paratext in the context of translation, the Part 1 would be better structured if it had started with Gennette's original conceptualization in literature, through conceptual expansion in digital world and then finally to paratext in the field of translation. Structured in this way, the inspiration of paratext studies in digital world, which is more advanced as shown before, for those in translation can be better analysed. In the existing book, there is few analysis of possible interaction between these two fields in terms of paratext though there are increasing connections between them as more and more translation and its paratext appear in the form of digit instead of print.

In conclusion, this book starts with examining the concept of paratext as it is proposed by Genette, highlighting its potential and internal conflicts hidden; it goes on to present three cases studies, showing how paratext is studied for different materials in different context, implying that the concept of paratext can be well applied into study of various materials and modified accordingly. It ends with reconceptualizing paratext for translation studies from a functional perspective and discussing the existing and prospective researches.

\section{References}

Batchelor, K. (2018). Translation and paratexts (translation theories explored). Milton Park, Abingdon-on-Thames, Oxfordshire United Kingdom: Taylor and Francis. Kindle.

Genette, G. (2010). Paratexts: Thresholds of interpretation (literature, culture, theory). Cambridge: Cambridge University Press. Kindle . 